\title{
The Effect of a Home-Based Strength Training Program on Type 2 Diabetes risk in Obese Latino Boys
}

Authors: Louise A. Kelly $\mathrm{PhD}^{*+}$, Armando Loza BSc ${ }^{* *}$, Xiao Lin BSc ${ }^{* *}$, E Todd Schroeder $\mathrm{PhD}^{* * *}$, Adrienne Hughes $\mathrm{PhD}^{* * * *}$, Alison Kirk PhD ${ }^{* * * *}$, Ann-Maire Knowles $\mathrm{PhD}^{* * * *}$.

Institutional Affiliations: *Department of Exercise Science, California Lutheran University, Thousand Oaks, CA. ${ }^{* *}$ Department of Preventive Medicine, Keck School of Medicine, University of Southern California. ${ }^{* * *}$ Division of Biokinesiology and Physical Therapy, School of Dentistry, University of Southern California, ${ }^{* * * *}$ School of Psychological Sciences and Health, Strathclyde University, Glasgow Scotland, UK.

Running title: Strength training and Type 2 Diabetes risk

+Address correspondence:

Louise A. Kelly, PhD

Exercise Science Department

California Lutheran University

60 W. Olsen Road, \#3400

Thousand Oaks, CA. 91360

Email: lakelly@callutheran.edu; Telephone: (805) 493-3547; Fax: (805) 493-3860

Key Words: Latino, Type 2 Diabetes, Pediatric, Exercise, Strength Training, insulin resistance, insulin sensitivity

Abbreviations:

HBST - Home Based Strength Training

SI- Insulin Sensitivity

DI - Disposition Index

AIR - Acute Insulin Response to Glucose

DEXA - dual energy X-ray absorptiometry

MI - Motivational Interviewing

Funding Support: National Institute of Cancer (NCI), University of Southern California Transdisciplinary Research on Energetics and Cancer (U54 CA 116848).

Financial Disclosers: The authors have no financial relationships relevant to this article to disclose.

Conflicts of Interest: The authors have no conflicts of interest relevant to this article to disclose."

Clinical Trail Registration Number: NCT01441323 


\section{What is know about this subject:}

As with adults, obesity in children is associated with development of T2DM. T2DM is now increasing in the pediatric population. It is well established that exercise training increases insulin sensitivity in normal and insulin resistant adults.

Word Count -36

\section{What this study adds:}

Studies in the pediatric population are laboratory based and therefore may not be sustainable once the study ends. To our knowledge we are the first group to conduct a home-based strength-training program to reduce diabetes risk in obese adolescent boys. Word Count - 40

\section{Contributions Statement :}

Kelly was responsible for study concept and design, statistical analysis, and obtaining funding Kelly Loza and Lin were responsible for data Acquisition. Kelly and Schroeder were analysis and interpretation of data and they provided study supervision Kelly, Loza, Lin, Schroeder, Kirk, Hughes, Knowles were responsible for drafting the manuscript and for the Critical revision of the manuscript for important intellectual content All authors approved the final manuscript as submitted and agree to be accountable for all aspects of the work.

Ethics: The Institutional Review Board of the University of Southern California approved this study, and all procedures were performed in accordance with standards outlined in the Helsinki Declaration.

Data Sharing: There is no additional data available 


\begin{abstract}
OBJECTIVE: to determine the effects of a HBST intervention on insulin sensitivity, compensatory acute insulin response and $\beta$-cell function, body composition measures and maximum strength in obese Latino boys.

METHODS: 26 obese Latino males aged 14-18 years were randomized to either a twiceweekly Home Based Strength Training group (HBST; $n=15)$ or a Control group (C;

$\mathrm{n}=15$ ) for 16 weeks. HBST for 16 weeks, composed of two one- hour sessions per week. Outcome Measures were assessed pre-and post intervention/control condition and included insulin sensitivity(SI), acute insulin response to glucose(AIR) and disposition index(DI), fasting glucose, two-hour glucose, body composition using waist -hip circumferences, Body Mass Index(BMI), dual energy X-ray absorptiometry(DEXA) scan, blood pressure and strength by 1-repetition maximum. A repeated measures GLM was used to assess differences in changes in outcome measures, between the $\mathrm{C}$ and the HBST groups.

RESULTS: There were no significant overall intervention effects on any of the outcome variables $(\mathrm{p}<0.05)$.

CONCLUSION: These results suggest that a home based strength training program does not -improve insulin sensitivity, maximal strength or decrease adiposity in obese Latino boys.
\end{abstract}




\section{INTRODUCTION}

The obesity epidemic has affected children and adolescents across the developed and developing world. In most of the world, obesity is now the most common pediatric disease (1-6). As with adults, obesity in children is associated with development of Type 2 diabetes. Previously considered an adult disease, T2DM is now increasing in the pediatric population $(8,9)$.

As with adults, T2DM in children is strongly associated with obesity. In addition to obesity, other risk factors include prenatal influences, age, sex, sedentary behavior, family history (10), transient pubertal insulin (11) resistance and ethnicity. The prevalence of obesity and T2DM is even more pronounced in ethnic populations, particularly in Hispanic youth (7). Mexican-American adolescents are more likely to be at risk of overweight or overweight than non-Hispanic white adolescents(7). Research has shown that insulin sensitivity is lower in overweight Latino adolescents compared with overweight Caucasian children independent of adiposity(12); disposition index is significantly lower in Latino children with impaired glucose tolerance compared with normal glucose tolerant children(13). Impaired fasting glucose is significantly associated with impaired $\beta$-cell function in overweight Latino adolescents with a family history of type 2 diabetes (14), and a decline in insulin sensitivity over time is unrelated to changes in body fat or maturation (15). It is well established that endurance exercise training increases insulin sensitivity in normal and insulin resistant individuals $(16,17)$. However, some find this form of exercise monotonous and it may also prove difficult for obese people. Strength training, by increasing muscle mass and endurance, may cause a more 
rapid change in body composition and improvements in functional status may prove to be more appealing, particularly to the obese population. Furthermore, strength training has been shown to improve insulin sensitivity by similar in magnitude to those observed following endurance exercise training (18). A number of studies have shown strength training to be effective at improving insulin sensitivity in participants with $\operatorname{T} 2 \mathrm{DM}(19,20)$ and in obese Latino adolescents (21).

Although these findings support the use of strength training as an exercise modality for the prevention and treatment of T2DM, it is unclear whether improvements in insulin sensitivity can be achieved/maintained once supervision is withdrawn. Most trials have used highly supervised exercise sessions usually in a clinical laboratory setting, with the aim of testing the effectiveness of strength training on metabolic parameters. However, the location of the delivery may influence long-term compliance and health outcomes. One potential strategy for improving compliance could be a home-based strength training approach, as it may foster long-term adherence through greater convenience and flexibility for the participant ${ }^{22}$. The home environment may be critically important because it influences the eating and activity behaviors in children $(23,24)$ and plays an important role in both the prevention of obesity and obesity co-morbidities $(25,26)$. Although extensive research suggests the home environment plays a substantial role in the development of childhood obesity, studies conducting physical activity interventions in the home environment are limited. To our knowledge, we are the first to deliver a home-based strength-training program specifically aimed reducing obesity and T2DM risk in a pediatric population. Therefore, the aims of the present study were two-fold, (a) 
to test the feasibility of conducting a novel home-based strength training (HBST)

intervention vs. control group (C); and 2) to determine the effects of a HBST intervention on insulin sensitivity, compensatory acute insulin response and $\beta$-cell function, body composition measures and maximum strength in obese Latino boys.

\section{REASEARCH DESIGN AND METHODS}

\section{Participants}

Thirty-two male participants were recruited from the greater Los Angeles County through medical clinics, advertisements, and local schools to participate in the FUERSA study (Families United for Education and Research for Strong Adolescent Latinos). Participants were consented to the study if they met the following study inclusion criteria: 1) male; 2) grades $9^{\text {th }}$ thru $12^{\text {th }}$ (approximately $14-18$ years of age); 3) with a BMI $\geq 95^{\text {th }}$ percentile for age and sex (CDC, 2000) (27); 4) of Latino ancestry (parents and grandparents descent as determined by self-report); 5) absence of diabetes using established guidelines (28); 6) have a positive family history of type 2 diabetes (determined by parental self-report), and 7) pubic hair Tanner stage $\geq 3$. Participants were excluded based on the following criteria: 1) were using medication or were diagnosed with any syndrome or disease that could influence dietary intake, exercise ability, body composition and fat distribution, or insulin action and secretion; 2) previously diagnosed with any major illness since birth (e.g. severe intrauterine growth retardation, chronic birth asphyxia, cancer); 3) had an orthopedic problems that would inhibit their ability to perform strength training exercise or 4) participated in a structured strength training program in the past 6 months. The study was conducted in accordance with the guidelines 
in the Helsinki Declaration. The Institutional Review Board of the University of Southern California approved this study. Written informed consent and assent were obtained from both the parents and children before testing began.

\section{Study Design}

After completion of the outpatient and inpatient visits subjects were randomized into one of two groups, 1) the home-based strength training group or the control group. All follow-up testing was completed within 48-72 hours after the last strength training session. At both pre- and post-testing, participants completed an outpatient and an inpatient visit.

\section{Outpatient Visit.}

Participants arrived at the USC General Clinical Research Center (GCRC) at 7:30 am after an overnight fast (nothing to eat or drink after $8 \mathrm{pm}$ ). A licensed pediatric health care provider conducted a detailed medical history exam and determined Tanner staging using established guideline (29). Following the exam, a 3-hour oral glucose tolerance test (OGTT) was conducted. This test included the application of a topical anesthetic to one arm and approximately 30 minutes later a flexible intravenous (iv) catheter was placed in an antecubital vein. Subjects then ingested $1.75 \mathrm{~g}$ oral glucose solution / $\mathrm{kg}$ body weight (to a maximum $75 \mathrm{~g}$ ). Blood samples were drawn at baseline and every 10 minutes for 3 hours. A total of 18 samples were collected and were assayed for glucose, insulin, and cpeptide. Fasting and 2-hr glucose levels were used to determine normal glucose tolerance (2-hour glucose $<140 \mathrm{mg} / \mathrm{dl}$ ) or impaired glucose tolerance (2-hour glucose $\geq 140$ and 
$<200 \mathrm{mg} / \mathrm{dl}$ ) as defined by the American Diabetes Association ${ }^{28}$. One prospective participant had type 2 diabetes and was excluded from the study and referred to his primary care physician. Three-hour insulin area under the curve (AUC) and incremental insulin area under the curve (IAUC) were calculated from the OGTT data, in $\mathrm{nmol} / \mathrm{L} / \mathrm{min}$.

\section{In-patient Visit.}

Approximately 7-14 days following the out-patient visit, participants were admitted to the GCRC and served a standardized dinner and an evening snack. At approximately 7:30 am the following day, an insulin-modified frequently sampled intravenous glucose tolerance test (FSIVGTT) was performed. At time 0 , glucose ( $25 \%$ dextrose, $0.3 \mathrm{~g} / \mathrm{kg}$ body wt) was

administered intravenously. Blood samples were collected at time points $-15,-5,2,4,8$, $19,22,30,40,50,70,100$, and 180 min. Insulin ( 0.02 units/kg body wt, Humulin R [regular insulin for human injection]; Eli Lilly, Indianapolis, IN) was injected intravenously at $20 \mathrm{~min}$. Plasma collected during the FSIVGTT was analyzed for glucose and insulin, and values were entered into the MINMOD Millenium 2003 computer program (version 5.16, Richard N. Bergman, USC) to determine insulin sensitivity (SI), acute insulin response (AIR, i.e., insulin area under the curve above basal for the first 8 min of the frequently sampled intravenous glucose tolerance test), and disposition index (DI, i.e. the product of insulin sensitivity $\mathrm{x}$ acute insulin response, an index of pancreatic B-cell function). 


\section{Assays}

Fasting and 2-hour samples taken during the OGTT for clinical diagnosis were separated for plasma and immediately transported on ice to the Los Angeles County-USC Medical Center Core Laboratory where glucose was analyzed on a Dimension clinical chemistry system using an in vitro hexokinase method (Dade Behring, Deerfield, IL.). Blood samples from all time points taken during the OGTT and FSIVGTT were centrifuged immediately for $10 \mathrm{~min}$ at $2500 \mathrm{RPM}$ and $8-10^{\circ} \mathrm{C}$ to obtain plasma, and aliquots were frozen at $-70^{\circ} \mathrm{C}$ until assayed. Glucose was assayed in duplicate on a Yellow Springs Instrument 2700 Analyzer (Yellow Springs Instrument, Yellow Springs, OH) using the

glucose oxidase method. Insulin was assayed in duplicate using a specific human insulin ELISA kit from Linco (St. Charles, MO), intra-assay coefficient of variation 4.7-7.0\%, interassay coefficient of variation 9.1-11.4\%, and cross-reaction with human proinsulin $0 \%)$.

\section{Strength Assessment}

Upper- and lower-body strength were assessed by 1 repetition maximum (1-RM) in the bench press and leg press, respectively, using established procedures (30). This data was used to determine the dose of strength training program. 


\section{Anthropometric Measures, Body Composition, and Tanner Stage}

Height was measured with a stadiometer to the nearest $0.1 \mathrm{~cm}$. Body weight was measured without shoes and in a hospital gown to the nearest $0.05 \mathrm{~kg}$ using a beam medical scale. Body mass index (BMI) was calculated; age- and sex-specific BMI percentile was determined using EpiInfo 2000, Version 1.1 (CDC, Atlanta, GA). Waist circumferences were measured using anthropometric tape. A dual-energy X-ray absorptiometry (DEXA) scan (Hologic QDR 4500W; Bedford, MA) was performed to estimate total fat mass (FM), and total lean tissue mass (LTM). All scans were completed by technicians who were fully trained in the operation of the scanner, the positioning of participants, and analysis of results according to the manufacturer's guidelines.

\section{Description of Intervention}

\section{Home Based -Strength Training (HBST)}

The HBST intervention was delivered in the participants' homes. Prior to the first exercise session, the personal trainers visited the participant's homes to evaluate the home environment in order to personalize the strength-training program. Participants were phoned once a week in order to monitor adherence to the program and also help maintain participant motivation and evaluate their progress. The personal trainers visited the participants once every four weeks to further motivate and evaluate participant's progress. The personal trainers also used Motivational Interviewing (MI) strategies to assist the subjects in: a) determining realistic physical activity goals; b) identifying their own strategies to reach these goals, and, c) ways to monitor behavior changes (31). Each participant received 4 individual motivational interviewing (MI) sessions by phone 
(approximately 10 minutes long) throughout the 16 week program by trained research staff. In order to test the feasibility of the program, participants were asked to text start and finished times for each exercise session directly to LK. This data was used to monitor adherence to the program. Furthermore, all participants received a handbook and a DVD in English and Spanish containing a written and visual descriptions of all exercises.

The strength training program was a 16-week intervention comprising of 3 "periodized" phases and took place over two non-consecutive days per week (e.g. Monday and Wednesday or Tuesday and Thursday) and did not exceed 1 hour in duration). Phase 1 (wks 1-4) consisted of 1 set of exercises with 10-15 repetitions at light to moderate intensity. Phase 2 (wks 5-10) consisted of 2-3 set of exercises with 13-15 repetitions at a moderate intensity and Phase 3 (wks 11-6) consisted of 3-4 set of exercises with 8-12 repetitions at moderate to high intensity. For the 2 non-consecutive training days, day 1 consisted of compound lower body exercises and isolated upper body exercises and day 2 included compound upper body exercises and isolated lower body exercises.

\section{Control Group (C)}

Children randomized to the $\mathrm{C}$ group received no intervention between pre- and post-data collection. Participants were asked not to participate in any other research program or participate in any structured activity program until completion of this intervention. The rationale for including controls in this pilot study is to assess "background changes" due to growth and/or other natural factors. Control group participants were eligible to receive the HBST program once post-data collection was completed. 


\section{Randomization}

Allocations were concealed from participants and all study personal (except LK) until after they completed the baseline outpatient and in-patient visit. Thirty-two participants were randomized into one of two groups.

\section{Sample Size Considerations.}

Our power calculation estimated that a mean difference in insulin sensitivity between of around $\geq 0.57$ units between groups would be detectable with $80 \%$ power at a significance 0.05 , in a sample size of $26-30$ pairs of children.

\section{Statistical Analyses}

All data were checked for normality prior to statistical analysis using descriptive statistics, histograms with normal distribution curves and using Anderson-Darling (A.D) normality tests. In order to identify possible randomization imbalance, across-group comparisons of baseline characteristics were conducted for evaluable participants using ANOVA. Wilcoxon signed rank-tests were used to test for significance differences between pre-post data. A repeated measure GLM was used to assess differences in changes in outcome measures, between the $\mathrm{C}$ and the HBST groups across time. For fat mass, lean mass was included as a covariate, and vice versa. For acute insulin response, insulin sensitivity was also included as a covariate. All analyses were conducted using SPSS version 20 for Mac (SPSS, Inc, Chicago, IL) with $\alpha$ set at 0.05 . 


\section{RESULTS}

\section{Characteristics of Participants}

Thirty-two participants were consented into the study and randomized into one of two groups. Final analysis was conducted on 26 participants (age $15.41 \pm 0.92$ years), 13 control and 13 in the HBST group. At post testing six participants did not complete the study for the following reasons 4 did not want to participate anymore and 2 did not want to do the clinical testing. All participants were obese (BMI $33.36 \pm 5.68 \mathrm{~kg} / \mathrm{m} 2$ and BMI percentile $97.58 \pm 2.03 \%$ ). There were no statistically significant group differences at baseline in any of the anthropometric, body composition or glucose or insulin sensitivity measures between ( $p>0.5$; see Table 1 and Table 2).

\section{Anthropometric, body composition and strength variables}

Variables related to anthropometrics, body composition by DEXA and strength training data are presented in Table 3. Over the 16 weeks of the intervention there were no significant across group differences for height, body weight $(\mathrm{p}=0.27), \mathrm{BMI}(\mathrm{p}=0.17)$, systolic blood pressure $(\mathrm{p}=0.15)$ or diastolic blood pressure $(\mathrm{p}=0.83)$. There were also no significant across group affects for waist circumference $(\mathrm{p}=0.30)$, hip circumference, lean mass $(\mathrm{p}=0.53)$ or $\%$ body fat $(\mathrm{p}=0.45)$. There was a significant across group affect for total fat mass with the $\mathrm{C}$ group having significantly less total fat mass at follow up compared to the HBST group ( $\mathrm{p}=0.04)$. In the control group, there were no significant differences between baseline and follow-up testing for 1RM bench press $(p=0.76)$ or 1RM leg press $(\mathrm{p}=0.33)$. In the HBST group there was a trend for an increase in 1RM 
bench press $(0.07)$ but no significant increase in $1 \mathrm{RM}$ leg press $(\mathrm{p}=0.19)$. There were no significant between group differences in either strength variable ( $p>0.05)$.

\section{Insulin Sensitivity/Dynamics}

Characteristics for insulin/glucose dynamics and metabolic values are shown in Tables 2 and Table 4. Over the 16 weeks of the intervention there were no significant withinsubject's differences for fasting glucose $(\mathrm{p}=0.87), 2$-hr glucose $(\mathrm{p}=0.38), \mathrm{SI}(\mathrm{p}=0.21)$, AIR ( $\mathrm{p}=0.49)$, and DI $(\mathrm{p}=0.95)$. There were also no between subject differences noted in fasting glucose ( $\mathrm{p}=0.36), 2$-hr glucose $(\mathrm{p}=0.84), \mathrm{SI}(\mathrm{p}=0.34), \mathrm{AIR}(\mathrm{p}=0.27)$, and DI $(\mathrm{p}=0.73)$.

\section{Process evaluation}

Of the prescribed sessions for the strength-training program, the HBST group reported completing $89 \%$ of the prescribed number of sessions.

\section{DISCUSSION}

Insulin resistance is one of the major complications of obesity in adults and children. Therefore, identifying interventions aimed at improving insulin sensitivity are necessary for preventing the metabolic diseases associated with obesity. Our intervention was designed to decrease obesity and improve insulin sensitivity, compensatory acute insulin response and $\beta$-cell function, body composition measures and maximum strength in 
obese Latino boys. Despite rigorous implementation we found no significant effect of the intervention on any of our outcome measures. However, the current study did show that the home-based strength training program was very well tolerated by the adolescent participants. To our knowledge this is one of the first studies to implement a HBST study in obese at-risk for T2DM Latino adolescents and therefore is an important addition to the evidence base.

The results of our study somewhat contradict those found by Bell and colleagues (32). While this study found that an 8-week circuit-training program improved insulin sensitivity, they also reported no changes in body composition and high attendance rates. It is worth noting that this study was a tightly controlled laboratory study while ours was home based. This study also included children of both sexes and the age range may have been affected by transient puberty. Similarly, Dunstan and colleagues using a 12 month HBST program in 36 elderly participants found the program was effective for maintaining muscle strength and lean body mass but did not show any improvements in insulin sensitivity (33).

In contrast, Shiabi and colleagues reported overweight Latino adolescents in a 16 week tightly controlled laboratory based strength training program significantly improved upper and lower body strength and insulin sensitivity when compared to the control group. However, this study also found no significant improvements in fasting insulin, insulin secretion (AIR) or $\beta$-cell function (34). Treuth and colleagues (35) studied obese girls over a 5-month duration laboratory based study and found an increase in overall 
body fat and insulin as measured by the oral glucose tolerance test (OGTT), but these improvements were not significant. Conflicting findings from a number of studies are likely due in part to the differences in study designs, study populations and outcome measures.

There are several limitations to our study worth noting. Firstly, was we used a relatively small sample size of adolescents $(n=26)$. However, the limitation of a small sample size is somewhat offset by precise measures of body composition (DXA), glucose and insulin values (OGTT) and the use of an understudied, high-risk population. The fitness levels of our participants were not measured. It has been suggested that in overweight middle school children fitness and not fatness is a better indicator of fasting insulin levels (35). Sedentary behavior was also not assessed and remarkably, exercise alone may not attenuate insulin resistance if sedentary activity is excessive; time spent being sedentary is predictive of high fasting insulin levels, regardless of the time spent doing moderate-tovigorous intensity activities, independent of age, sex, fat mass, fasting insulin, smoking status, and follow-up time. It would have been prudent to include assessments of readiness to change and may be of vital importance as we also saw some improvements for several outcome measures in the control group. This may have resulted in some control participants engaging in exercise or changing diet despite the explicit instruction to main their "normal" lifestyle for the study duration. The absence of any nutrition education or intervention, may have contributed to our null findings. However, several recently published tightly controlled laboratory pediatric studies using strength training and nutrition education in overweight Latino and African American adolescents did not 
find any significant improvements of insulin sensitivity or body composition (36-38).

Several studies have also noted that parents and family members should be included in interventions with children, particularly if they are from low-income families $(39,40)$. Our study focused on the child only, we may have seen greater improvements if we had included family. Finally, the dose duration was self-reported, thus it may be possible that the participants over-reported occurred, while the participants sent texts to LK stating start time and completion time of each exercise session there was no real way of knowing if they were actually exercising during this period. It may also be feasible that the dose and duration were too low to make changes necessary to improve insulin sensitivity.

In conclusion, this home-based strength training program, while apparently well tolerated by the obese adolescents did not result in the expected improvements in obesity and diabetes risk. Successful population-based approaches to addressing the childhood obesity epidemic may require more intensive interventions in various settings, and should include the entire family not just the child. Further research is necessary to identify successful and sustainable interventions for obesity and type 2 diabetes prevention in obese Latino children.

\section{Acknowledgements}

This work was supported by the National Institute of Cancer (NCI), University of Southern California Transdisciplinary Research on Energetics and Cancer (U54 CA 116848). We are grateful to the nurses and nutrition staff at the USC-GCRC. Finally, we express our gratitude to the children and their families for making this study possible. 


\section{REFERENCES}

1. Reilly JJ, Dorosty AR. Epidemic of obesity in UK children. Lancet 1999;354:1874-5.

2. Reilly JJ, Dorosty AR, Emmett PM. Prevalence of overweight and obesity in British children: cohort study. BMJ 1999;319:1039.

3. Strauss RS, Pollock HA. Epidemic increase in childhood overweight 1986- 1998. JAMA 2001;286:2845-8.

4. Lobstein T, Baur L, Uauy R. Obesity in children and young people: a crisis in public health. Obes Rev 2004;5(suppl 1):4-85.

5. de Onis M, Blossner M. Prevalence and trends of overweight among preschool children from developing countries. Am J Clin Nutr 2000;72:1032-9.

6. Martorell R, Kettel-khanL, Hughes ML, et al. Overweight and obesity in preschool children from developing countries. Int J Obes 2000;24:959-67.

7. Ogden CL, Carroll MD, Curtin LR, McDowell MA, Tabak CJ, Flegal KM. Prevalence of overweight and obesity in the United States, 1999-2004. JAMA. 2006;295(13):1549-1555.

8. Alberti G, Zimmet P, Shaw J, Bloomgarden Z, Kaufman F, Silink M. Type 2 diabetes in the young: the evolving epidemic: the international diabetes federation consensus workshop. Diab Care 2004 27: 1798-1811.

9. Ehtisham S, Barrett TG, Shaw NJ. Type 2 Diabetes mellitus in UK children - an emerging problem 2000 17: 867-871.

10. Kelly LA, Lane C, Weignesberg MJ, Koebnick C, Roberts CK, Davis JN, ToledoCorral CM, Shaibi GQ, Goran MI. Parental History and risk of type 2 diabetes in overweight Latino adolescents: A longitudinal analysis. Diabetes Care. 2007; 30: 2700-2750.

11. American Diabetes Association. Type 2 diabetes in children and adolescents. Pediatrics. 2000; 105: 671-680.

12. Goran MI, Bergman RN, et al: Insulin resistance and associated compensatory responses in African American and Hispanic children. Diabetes Care 2002; 25(12):2184-90.

13. Goran MI, Bergman RN, et al: Impaired glucose tolerance and reduced beta-cell function in overweight Latino children with a positive family history for type 2 diabetes. J Clin Endocr Met 2004; 89(1):207-12.

14. Weigensberg MJ, Ball GD, et al: Decreased beta-cell function in overweight Latino children with impaired fasting glucose. Diabetes Care 2005; 28(10):2519-24.

15. Goran MI, Shaibi GQ, Weigensberg MJ, Davis JN \& Cruz ML. Deterioration of insulin sensitivity and beta-cell function in overweight Hispanic children during pubertal transition: A longitudinal assessment. IJPO. 2006; 1 (3): 139 - 145, 2006.

16. Sigal RJ, Kenny GP, Wassweman DH, et al., Physical activity/exercise and type 2 diabetes; a consensus statement from the American Diabetes Association. Diabetes Care. 2006; 29: 1433-1438.

17. Henriksen EJ: Invited review: Effects of acute exercise and exercise training on insulin resistance. J Appl Physiol 93:788-796, 2002.

18. Ivy JL: Role of exercise training in the prevention and treatment of insulin resistance and non-insulin-dependent diabetes mellitus. Sports Med 24:321-336, 1997. 
19. Tokmakidis SP, Zois CE, Volaklis KA, Kotsa K, Touvra AM. The effects of a combined strength and aerobic exercise program on glucose control and insulin action in women with type 2 diabetes. Eur J Appl Physiol. 2004; 92:437-42.

20. Eriksson J, Taimela S, Eriksson K, Parviainen S, Peltoen J, Kujala U. Resistance training in the treatment of non-insulin-dependant diabetes mellitus. Int J Sports Med. 1997; 18: 242-6.

21. Shaibi GQ, Cruz ML, Ball GDC, Weigensberg MJ, Crespo NC, Salem GJ, \& Goran MI Effects of resistance training on insulin sensitivity in overweight Hispanic adolescent males. Med Sci Sports Exerc 2006; 38 (7): 1208 - 1215.

22. King, AC, Blair SN, Bild DE, DIshman RK, Dubbert PM, Marcus BH, Oldridge NB, Paffenbarger RS JR, Powell KE, Yeager KK. Determinants of physical activity and interventions in adults. Med Sci Sports Exerc 1992; 24:S221-S236.

23. Crockett, S., Sims, L. Environmental influences on children's eating. Journal of Nutrition Education1995; 27:235-250.

24. Elder, J., Broyles, S., McKenzie, T., Sallis, J., Berry, C., Davis, T., Hoy, P., Nader, P. Direct home observations of the prompting of physical activity in sedentary and active Mexican- and Anglo- American children. Journal of Developmental \& Behavioral Pediatrics 1998; 19:26-30.

25. Epstein, L.H., Wing, R.R., Koseske, R., Andrasik, F., Ossip, D.J. Child and parent weight loss in family-based behavior modification programs. Journal of Consulting and Clinical Psychology 1981; 49:675-685.

26. Epstein, L.H. Family-based behavioral intervention for obese children. International Journal of Obesity 1996; 20:S14-S21.

27. Centers for Disease Control and Prevention: CDC growth Charts. Atlanta, GA, U.S. Department of Health and Human Services, Centers for Disease Control and Prevention, National Center for Health Statistics, 2000 (U.S. Publ. no. 314).

28. ADA (2000) Type 2 diabetes in children and adolescents. Pediatrics 105:671-680.

29. Marshall WA, Tanner JM. Variations in the pattern of pubertal changes in boys. Arch Dis Child. 1970; 45:13-23.

30. Faigenbaum AD, Milliken LA, Westcott WL: Maximal strength testing in healthy children. J Strength Cond Res. 2003; 17:162-166.

31. Miller WR, Rollnick S. Motivational Interviewing, 2nd edition: Preparing People for Change. New York: The Guilford Press; 2001.

32. Bell LM, Watts K, Saifarikas A, Thompson A, Ratnam N, Bulsara M, Finn J, O’Driscoll G, Green DJ, Jones TW, Davis E. Exercise alone reduces insulin resistance in obese children independelty of changes in body composition. J Clin Endocrin Meta. 2007, 92: 4230-4235.

33. Dunstan DW, Daly RM, Owen N, Jolley D, Vulikh E, Shaw J, Zimmet P. HomeBased Resistance Training Is Not Sufficient To Maintain Improved Glycemic Control Following Supervised Training In Older Individuals With Type 2 Diabetes. Diabetes Care. 2005, 28: 3-9.

34. Shaibi GQ, Cruz ML, Ball GDC, Weigensberg MJ, Crespo NC, Salem GJ, \& Goran MI Effects of resistance training on insulin sensitivity in overweight Hispanic adolescent males. Med Sci Sports Exer. 2006,38 (7): 1208 - 1215. 
35. Treuth MS , Hunter GR, Pichon C, Figueroa-Colon R, \& Goran MI Fitness and energy expenditure after strength training in obese prepubertal girls Med Sci Sports Exer. 1998. 30: 1130-1136.

36. Allen DB, Nemeth BA, Randall Clark R, Peterson SE, Eickhoff J, Carrel AL. Fitness Is A Strong Predictor Of Fasting Insulin Levels Than Fatness In Overweight Male Middle-School Children. Ped. 2007. 150: 383-387.

37. Davis JN, Kelly LA, Lane CJ, Ventura EE, Byrd-Williams CE, Alexander KA, Azen SP Chou CP, Spruijt-Metz D, Weigensberg MJ, Berhane K, \& Goran MI. Randomized control trial to reduce obesity related diseases in overweight Latino adolescents. Obesity. 2009. 17: $1542-1548$.

38. Hasson RE, Adam TC, Davis JN, Kelly LA, Ventura EE, Toledo-Corral C, ByrdWilliams C, Roberts CK, Lane CJ, Azen SP, Chou C, Spruijt-Metz, D, Weigensberg MJ \& Goran MI Randomized control trial to improve adiposity and insulin resistance in obese African American and Latino Adolescents. Obesity. 2012. 20 (4): 811-818, 201.

39. Alff F, Markert J, Zschaler S, Gausche R, Kiess W, Blüher S. Reasons for (non)participating in a telephone-based intervention program for families with overweight children. PLoS One. 2012;7(4):e34580.

40. Stewart L, Chapple J, Hughes AR, Poustie V, Reilly J. Parents journey through treatment for their child's obesity: a qualitative study. Arch Dis Childhood 93 (1): 3539. 